\title{
Determinação do parâmetro de intersecção de fraturas para o Aqüífero Atuba
}

\author{
Lilian Chavez-Kus ${ }^{1}$ \& Eduardo Salamuni ${ }^{2}$
}

\begin{abstract}
Resumo Com base no modelo estrutural proposto por Chavez-Kus (2003) e Chavez-Kus \& Salamuni (2008), $\sigma_{1}$ está ou esteve orientado na direção N-S na região de Curitiba. Neste contexto, foram realizados os cálculos de intersecção de fraturas, conforme os procedimentos computacionais desenvolvidos por Kim (2004) e Kim et al. (2004) com os planos considerados mais favoráveis para explotação de água subterrânea, ou seja N45W a N45E. O resultado indica que o parâmetro de intersecção nos cruzamentos dos planos conjugados e fraturas híbridas coincidem com valores altos de capacidade específica e vazão dos poços tubulares profundos. As falhas de grande porte que controlam os principais limites entre os blocos estruturais do Complexo Atuba, no embasamento da Bacia de Curitiba, estão sempre presentes onde ocorrem valores de intersecção também altos. A coincidência maior pode ser vista no cruzamento da falha do Belém com as demais estruturas. As propriedades hidráulicas do meio geológico e a produtividade dos poços tubulares não devem ser diretamente inferidas usando como critério somente as áreas próximas ou ao redor dos lineamentos. Mapas de densidade de fraturas apresentaram baixa correspondência com a produtividade dos poços. Em termos de favorabilidade para água subterrânea, o parâmetro de intersecção das fraturas, calculado por meio da extensão Lineament Analysis, é o que melhor evidencia correlação com as variáveis hidrogeológicas. Os resultados obtidos mostram que há grandes chances de se obter sucesso ao apontar as áreas favoráveis à circulação de água subterrânea na região quando o cálculo é feito de acordo com a trama estrutural mais recente.
\end{abstract}

Palavras-chave: Complexo Atuba, intersecção de fraturas, campo de tensão, morfotectônica, análise de lineamentos, tectônica recente, hidrogeologia.

\begin{abstract}
Fracture cross-point determination to the Atuba Aquifer. Based on the structural model proposed by Chavez-Kus (2003) and Chavez-Kus \& Salamuni (2008), $\boldsymbol{\sigma}_{1}$ was oriented in the N-S direction in the region of Curitiba. In this context, the calculations of lineament crosspoint were accomplished through the scripts developed by Kim (2004) and Kim et al. (2004). Only fractures that are most favourable for groundwater exploitation (N45W N45E) were considered. The obtained result indicates that intersection parameters in the crossings of conjugate and hybrid fractures coincide with high specific capacities and water flow rates of deep wells. The master faults, which control the geometry of the top of the basement of the Atuba Complex, are always present where high values of lineament crosspoint occur. The Belém fault shows the highest coincidence at crossing points with other structures. The hydraulic properties of the geological media in this area, and through this, the productivity of pumping wells, cannot only be estimated due to the proximity to local lineaments. In fact, fracture density does not correlate well with the productivity of the wells. The crosspoint fracture parameter, calculated through the extension Lineament Analysis, shows the best correlation to groundwater favourability. The obtained results illustrate that the identification of areas favourable for the circulation of groundwater is possible, when the calculation is made based on the most recent tectonic events.
\end{abstract}

Keywords: Atuba Complex, fracture cross-point, stress field, morphotectonic, lineament analysis, recent tectonic, hydrogeology.

INTRODUÇÃO O Aqüífero Atuba, representado pelas rochas do Complexo Atuba, é um sistema hidrogelógico de meio fissural heterogêneo e anisotrópico cuja circulação de água subterrânea se faz por meio de descontinuidades estruturais preferenciais decorrentes da atuação de sistemas transcorrentes associados ao campo de tensão atual ou pré-atual, caracterizado por uma compressão máxima horizontal $\left(\sigma_{1}\right)$ na direção N-S (Salamuni 1998, Chavez-Kus 2003 e 2008, Chavez-Kus \& Salamuni 2008).

Com esta premissa, procurou-se demonstrar que a maior favorabilidade hidrogeológica do aqüífero fraturado é condicionada, principalmente, pelo parâmetro intersecção, com peso ainda maior nos cruzamentos das estruturas rúpteis abertas de grande porte que fazem parte do sistema transcorrente antes mencionado. $\mathrm{O}$ reconhecimento do parâmetro das intersecções das fraturas, correlacionando-as com lineações que controlam a circulação de água, são considerados como informações importantes no que diz respeito ao zoneamento hidrogeológico na região. Para mostrar a correspondência entre o parâmetro intersecção e a maior ocorrência

1 - Bayerisches Landesamt für Umwelt, Abteilung 10 Geologischer Dienst, Referat 104 Hydrogeologie, Hans-Högn-Str. 12, Germany.

E-mail: lilian.chavez-kus@1fu.bayern.de

2 - Universidade Federal do Paraná, Departamento de Geologia, Curitiba (PR), Brasil. E-mail: salamuni@ufpr.br 
de água subterrânea aquele foi comparado, em mapas temáticos, aos valores reais medidos das variáveis vazão e capacidade específica dos poços tubulares profundos, havendo interessante correlação. Situação contrária ocorre ao ser gerado mapa apenas com o parâmetro densidade de fraturas, cujo resultado não apresenta boa correlação com os poços produtivos.

O cálculo das intersecções das fraturas foi realizado a partir da construção de mapas de densidade de intersecção de lineamentos, conforme os procedimentos computacionais desenvolvidos por Kim (2004) e Kim et al. (2004). A determinação deste parâmetro é extremamente dependente da escala de observação (Tripp \& Vearn, 2004). Neste contexto o traçado dos lineamentos partiu de uma análise regional com as imagens digitais em escala ampla e resolução de $90 \mathrm{~m}$, passando para a análise de detalhe com o MDR de resolução de 10 m. A partir destas diferentes escalas de observação, fez-se o reconhecimento das grandes estruturas tectônicas, ou seja, das falhas mestras e que correspondem a prováveis fraturas profundas, assim como das diferentes famílias de fraturas menores que cruzam a área, tendo como base as fotointerpretações iniciais de Salamuni (1998) e as interpretações em ambiente de SIG de Chavez-Kus (2003). Os lineamentos em SIG foram traçados a partir de imagens digitais sombreadas, com aplicação de iluminação artificial no modelo digital de relevo (MDR), nos azimutes de $0^{\circ}, 30^{\circ}, 45^{\circ}, 270^{\circ}, 315^{\circ}$ e $345^{\circ}$ e elevação de $45^{\circ}$. Ao utilizar-se a iluminação artificia, as pequenas variações superficiais foram realçadas, permitindo identificar lineamentos estruturais antes mascarados, como geralmente ocorre nos locais onde estão depositados os sedimentos da bacia sobre o embasamento. Aliado ao traçado de lineamentos estruturais em tela de computador, tendo como base o MDR, foi realizada a extração das feições lineares, tendo como referência os padrões e anomalias das drenagens reconhecidos de acordo com o conceito de Hobbs (1912) e Cristofoletti (1980). Os lineamentos presentes coincidem com drenagens, indicando que as mesmas estão fortemente controladas tectonicamente, formando grandes vales alinhados segundo direções preferenciais. Um mapa de lineações de drenagem elaborado por Salamuni (op. cit.) também foi consultado.

Localização da área $\mathrm{O}$ município de Curitiba e municípios circunvizinhos correspondem à área alvo da pesquisa e os principais acessos são as rodovias federais e as vias principais, conforme mostra a figura 1. Esta região está inserida no contexto geológico da Bacia Sedimentar de Curitiba, localizada na porção centro-sul do Primeiro Planalto Paranaense, cujo embasamento é o Complexo Atuba (Siga Jr. et al. 1995).

Análise dos lineamentos Como consideração geral, a abordagem sobre lineamentos parte do conceito de O'leary (1976) no qual estas estruturas são consideradas como feições lineares ou curvilineares mapeáveis, cujo padrão difere daqueles apresentados por feições adjacentes, refletindo um fenômeno de subsuperfície.

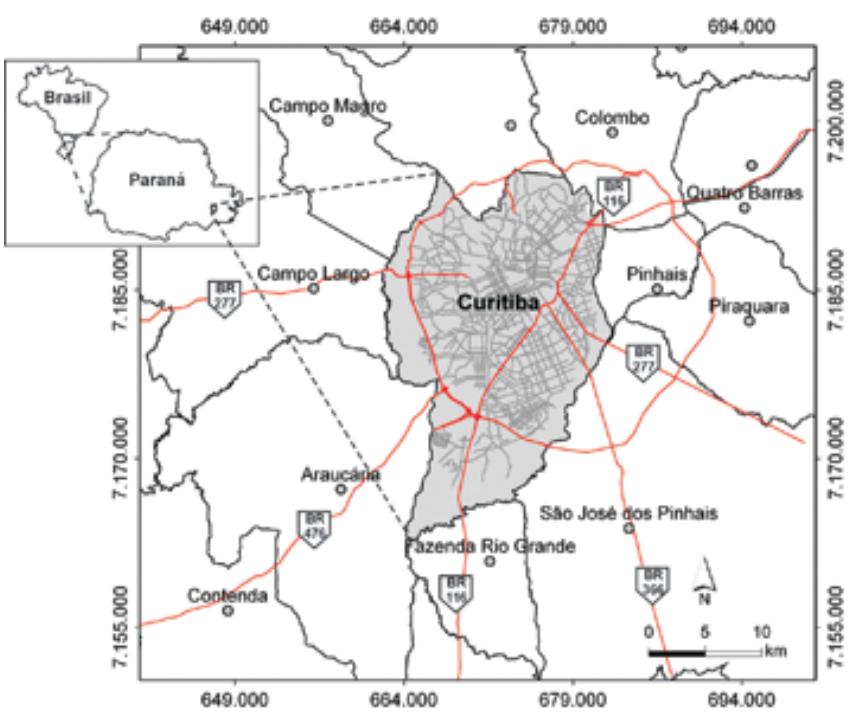

Figura 1 - Localização das principais vias de acesso à cidade de Curitiba e municípios circunvizinhos à área de estudo.

Originalmente o termo foi definido por Hobbs (1912) e utilizado por Allen (1975) para caracterizar as relações espaciais de feições e relevo retilíneas ou alinhadas. Entretanto, nem todos os lineamentos de relevo de um MDR condizem com alinhamentos estruturais, por exemplo, como os lineamentos que constituem a quebra positiva de grandes escarpas de erosão. Na área alvo, no entanto, como a tectônica tem papel decisivo na modelagem da paisagem, há grande similaridade da morfologia superficial com o topo do embasamento, cuja geometria é delimitada por grandes superfícies tectônicas. Tal hipótese é corroborada pelas principais conclusões, em termos estruturais, do trabalho de Salamuni (op. cit.) e Chavez-Kus (2008) neste volume e cujo o resultado serviu como referencial para gerar o mapa de lineamentos.

A ferramenta utilizada para a análise dos lineamentos (Lineament Analysis) e cálculo do parâmetro de intersecção foi criada por Kim (op. cit.) e desenvolvida especialmente para o programa ARCVIEW 3.2 com base na linguagem Avenue TM (os scripts contidos na extensão foram programados com código aberto, permitindo que o usuário realize modificações e/ou adaptações de interesse). A extensão Lineament analysis for geology and groundwater field pode ser atualmente obtida de forma livre a partir da página da WEB da ESRI (Environmental Systems Research Institute, Support Center) no endereço eletrônico: http://arcscripts.esri.com/.

Antes de iniciar os cálculos de densidade e pontos de intersecção dos planos, foi realizado o tratamento dos segmentos, buscando-se otimizar os parâmetros geométricos dos mesmos, conforme a seguinte seqüência:

a) Eliminação dos segmentos duplicados: a remoção dos traços duplicados é o primeiro passo em toda a análise de lineamentos e deve ser cuidadosamente realizada, evitando posteriormente erros de sobrestimação

b) Remoção de nós e generalização dos traços: 
no traçado dos lineamentos, os segmentos levemente curvos freqüentemente apresentam, ao longo do mesmo plano, diversos nós e os mesmo podem gerar erros estatísticos no cálculo. Nos planos pouco retilíneos, é possível determinar um ângulo máximo de curvatura, a partir do qual o traço é dividido em dois segmentos independentes. Na análise, adotou-se a variação máxima de $10^{\circ}$ para o parâmetro de retilinearidade dos lineamentos (Fig. 2).

c) Estatística dos lineamentos: nesta etapa é calculada automaticamente a estatística dos lineamentos, conforme o ângulo de busca desejado. Utilizou-se o valor de $10^{\circ}$, sendo gerado nestes intervalos o cálculo de frequência dos lineamentos. A partir destes, foi criado um gráfico de freqüências em barras e um diagrama de rosetas (Fig. 3) que permitem a visualização das direções de lineamentos de maior destaque. Dentre todas as direções obtidas, a família de lineamentos N-S é dominante, constituindo $17 \%$ de todos os valores.

d) Seleção dos segmentos de acordo com as direções desejadas: com base na análise estrutural dos dados de campo e na análise morfoestrutural, foi proposto em Chavez-Kus e Salamuni (op. cit.), para os planos de fraturas novos ou reativados em tempos recentes, um ajuste para o campo de tensão atual, segundo o modelo de Riedel (1929). O resultado desse ajuste indica o tensor principal posicionado a N-S, relacionando-o às falhas transcorrentes. Para o cálculo de densidade e intersecção dos lineamentos, foram realizados diversos testes e, finalmente, escolhidas apenas as direções dos planos, cujos valores ocorrem sistematicamente no intervalo de N45W/SE a N45E/SW, e aquelas das falhas de grande porte (Fig. 4).

O critério empregado para fazer a seleção pode ser explicado de acordo com o conceito de estruturas em splay ou em step. Em Chavez-Kus (2008), nos lineamentos observados em nível de detalhe, nas direções N45 a 60E e N60W, a origem da forma sigmoidal observada pode estar associada às estruturas do tipo step, denominadas desta forma por terem sido criadas e desenvolvidas ao longo de planos de fraturas préexistentes. A movimentação sucessiva ao longo de uma falha resulta não somente no prolongamento do traço da estrutura, mas também na propagação e crescimento lateral da mesma, havendo união entre os planos de fraturas adjacentes por meio dos planos em splay. Isso dá origem a zonas de falhas com geometria anastomosada, por exemplo, ou em echelon, sendo esse processo denominado de linkage (Cartwright et al. 1996, Martel \& Pollard 1989, Khang et al. 2004). Comparando-se o modelo conceitual dos autores com o modelo de Riedel (1929), verifica-se que as estruturas em splay ou em step corresponderiam às direções de $\mathrm{R}$ ou R' (Fig. 5). Segundo Smellie et al. (1995), Watanabe et al. (1997) e Yoshida et al. (2000), o fluxo da água subterrânea, em aquíferos fraturados, é controlado por falhas mestras de grande porte, enquanto que as fraturas em forma de step são as responsáveis pela conectividade do conjunto.

As mudanças na geometria de uma falha originam zonas localizadas de dilatação, direcionando o fluxo de fluídos e a ruptura das paredes das rochas durante

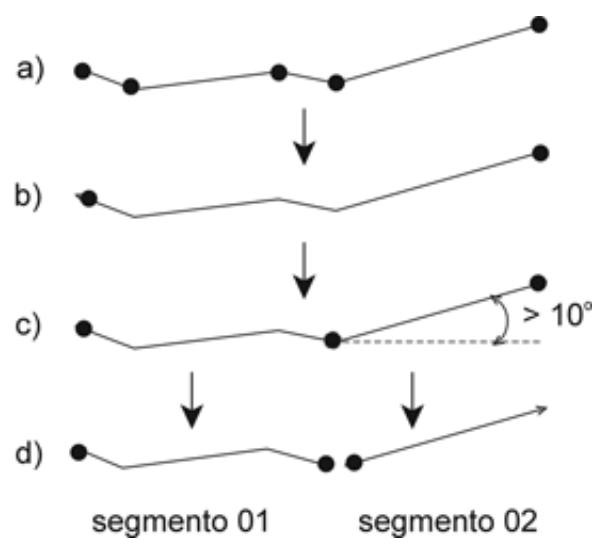

Figura 2 - Remoção de nós desnecessários e generalização dos segmentos.

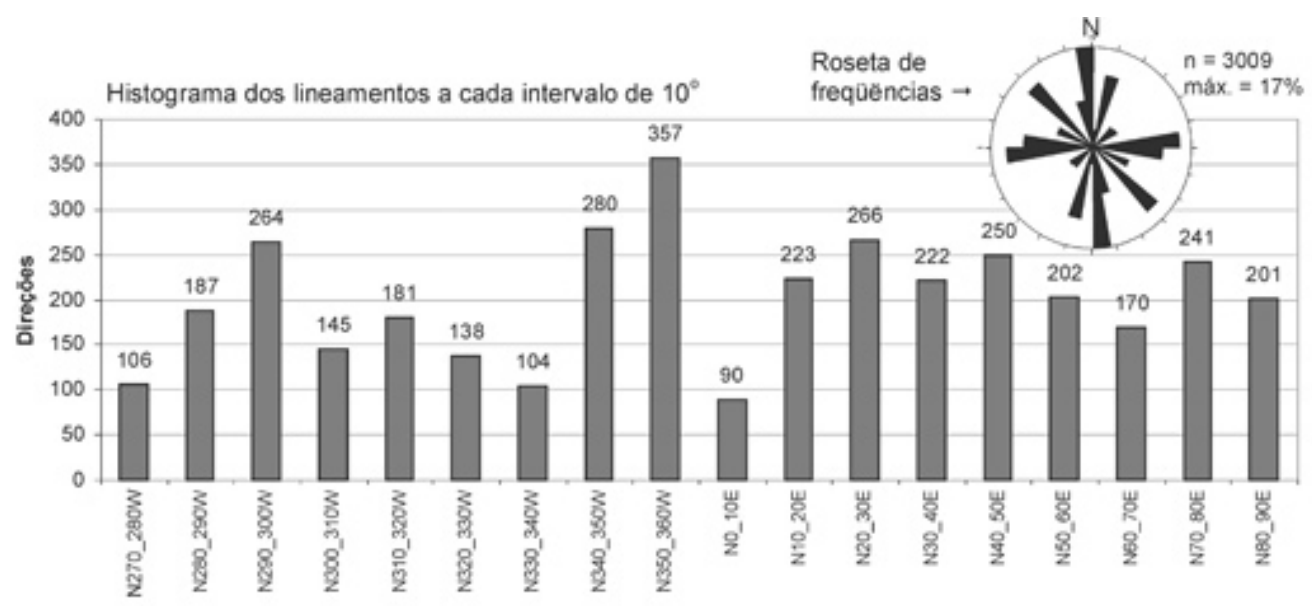

Figura 3 - Frequência dos lineamentos de acordo com um diagrama em barras e diagrama de rosetas. 


\section{Seleção dos segmentos de acordo com:}
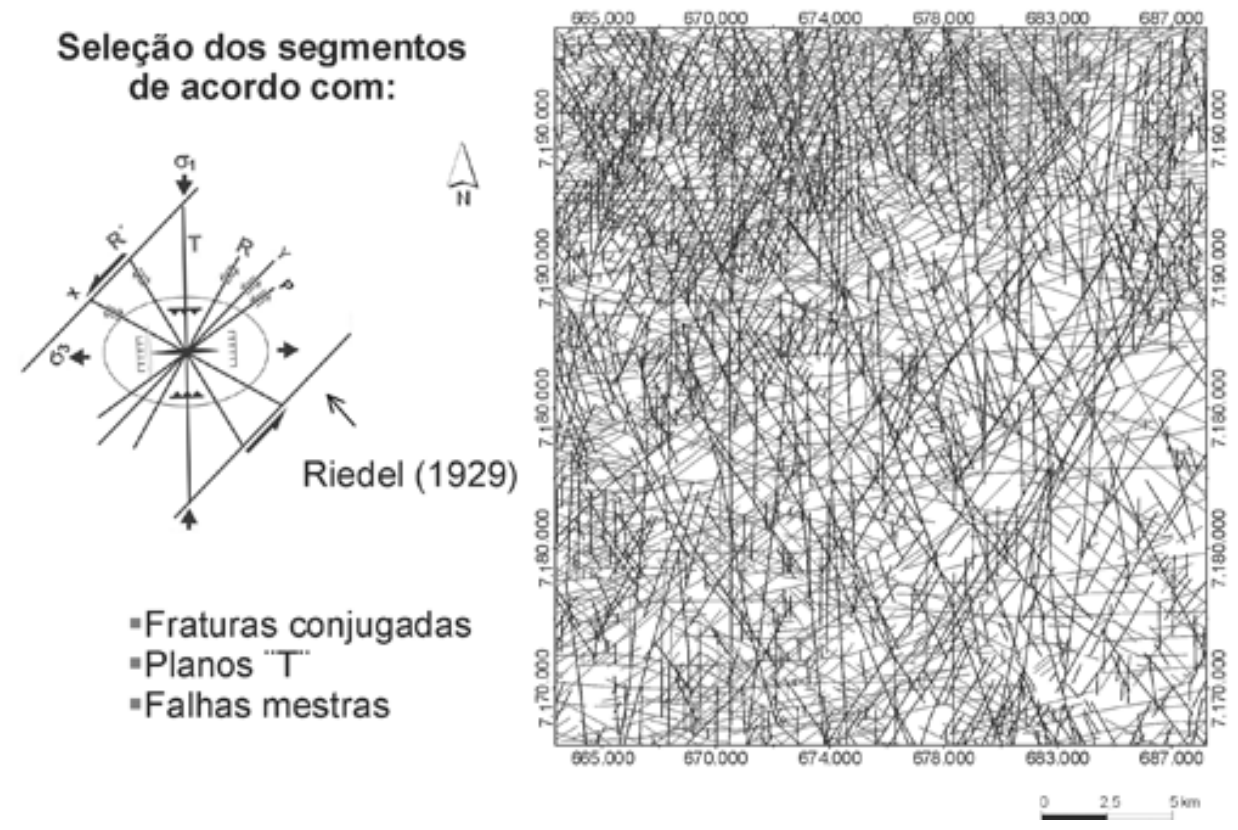

\section{-Fraturas conjugadas -Planos " $T$ -Falhas mestras}

Figura 4 - Esquema mostrando a área investigada e os lineamentos selecionados na análise de intersecção das fraturas.

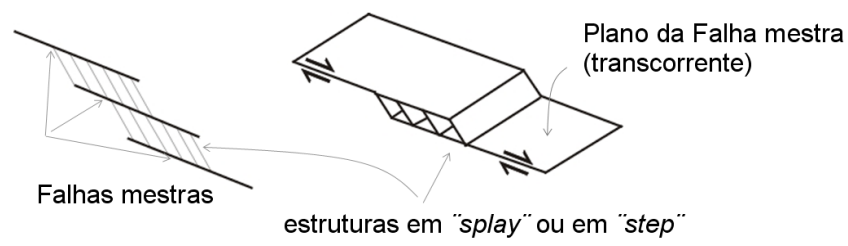

Figura 5 - Modelo conceitual do padrão das falhas mestras e estruturas em step (mod. Khang et al., 2004).

o movimento dos planos (Sibson 1987, Mccaig 1989, Connolly \& Cosgrove 1999). Os autores caracterizam estas áreas como right-hand bends ou left-hand-bends, sendo este conceito também semelhante ao utilizado para as estruturas anteriormente citadas e mostradas na figura 5. O padrão amendoado nas paredes de uma rocha onde ocorrem falhas do tipo step ou em splay vai produzir, de forma localizada, um intenso fraturamento, assim como a múltipla intersecção de falhas sincrônicas (da mesma época) em diferentes orientações, responsáveis pela alta densidade de fraturas na intersecção dos planos relacionados (Tripp \& Vearn 2004).

CÁlCULO DA DENSIDADE DE FRATURAS E PONTOS DE INTERSECÇÃO O procedimento computacional empregado a partir do script PL-DENS da extensão Lineament Analysis para o cálculo de densidade tem como base o método de Hardcastle (1995). Segundo esta técnica, é criada uma malha de pontos regular e, a cada nó, é construído um círculo, cujo raio de busca é estipulado pelo usuário (Fig. 6). Ao final da operação, é gerado um mapa de pontos (com coordena- das $\mathbf{x}$ e $\mathbf{y}$ ) correspondentes aos centros de cada círculo, os quais contêm as informações gravadas em uma tabela no fornato $d b f$. $\mathrm{O}$ exemplo de estrutura básica pode ser visualizado na tabela 1 .

Para visualizar a malha circular mostrada na figura 6, foi utilizado um outro script, de nome MILA GRID UTILITIES 1.3, obtido de forma livre no sítio eletrônico da ESRI. Com as informações contidas em cada nó, foi possível, utilizando-se o programa ARCVIEW 3.2 ou SURFER, reproduzir os valores de densidade ou intersecção de fraturas por meio de mapas de contornos. $\mathrm{Na}$ pesquisa, foram testados diferentes raios para os círculos de busca, com a preocupação de se evitar erros de sobrestimação ou subestimação. Quando se faz a contagem dos segmentos dentro de uma malha (circular, quadrada, entre outras) o que se mede é, na realidade, a densidade aparente, sendo este parâmetro dependente da escala em que é feita a amostragem, a exemplo do gráfico da figura 7. Verifica-se que quanto menor o raio do círculo, maior é a sobrestimação na análise.

Outro detalhe importante na amostragem circular é que os círculos sempre passam pelo centro do polígono vizinho, garantindo que as áreas sejam igualmente consideradas (Mauldon et al. 2001). Essa é a grande diferença da amostragem em malha circular em relação às áreas amostradas em malha retangular, na qual a subestimação ou sobrestimação dos lineamentos é maior e o recobrimento é menos eficiente (Fig. 8).

O parâmetro de densidade aparente é calculado somando-se o número de traços visíveis dentro do círculo e dividindo o resultado pela área desta malha de amostragem. Essa é a operação efetuada, por exemplo, na coluna CNTDENS gerada pela extensão Lineament Analysis. Mesmo que um lineamento apenas tangencie 


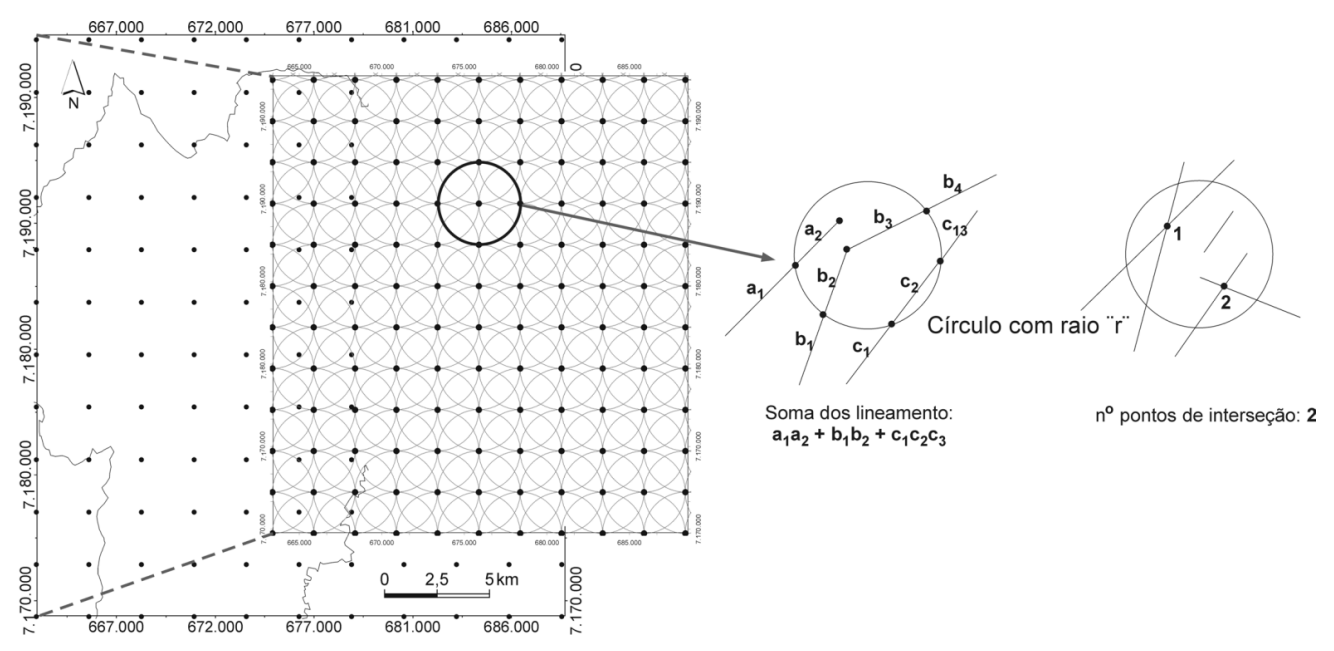

Figura 6 - Esquema que mostra o mapa de pontos gerado e grade circular correspondente, na qual cada nó contém as informações anteriormente descritas na tabela 1.

Tabela 1 - Exemplo da estrutura da tabela gerada no cálculo de densidade e intersecção de fraturas por meio do script PL-DENS, empregando raio de $250 \mathrm{~m}$. Onde LENSU corresponde à soma total do comprimento dos lineamentos; LENDENS é a densidade do comprimento do lineamento dentro círculo, dividido pela área do círculo (unidade: $\mathrm{km} / \mathrm{km}^{2}$ ); CNTSU à soma total do comprimento dos lineamentos; CNTDENS corresponde ao número total de lineamentos dividido pela área do círculo; INTERSECT corresponde ao número total de pontos de intersecção dos lineamentos; INTERDENS corresponde ao número de pontos de intersecção dos lineamentos divido pela área do círculo; 90 80 até 80 90 (azimute) correspondem aos valores angulares em cada intervalo.

\begin{tabular}{|c|c|c|c|c|c|c|c|c|c|c|c|c|c|}
\hline Ponto & $\begin{array}{c}\text { X } \\
\text { (coord.) }\end{array}$ & $\begin{array}{c}\mathrm{Y} \\
\text { (coord.) }\end{array}$ & Lensum & Lendens & Cntsum & Cntdens & Intersect & Interdens & N90-80W & N80-70W & & N70-80E & N80-90E \\
\hline 1 & 663358 & 7169305 & 0 & 0,00 & 0 & 0,00 & 1 & 5,09 & 0 & 0 & .. & 0 & 0 \\
\hline 2 & 663358 & 7169555 & 250 & 1,27 & 1 & 5,09 & 3 & 0,00 & 0 & 0 & .. & 0 & 0 \\
\hline 3 & 663358 & 7169805 & 548 & 2,79 & 2 & 10,19 & 0 & 0,00 & 0 & 0 & .. & 0 & 0 \\
\hline$\ldots .$. & $\ldots .$. & $\ldots .$. & $\ldots .$. & $\ldots .$. & $\ldots .$. & $\ldots .$. & $\ldots .$. & ..... & ..... & ..... & . & ..... & ..... \\
\hline 11535 & 688858 & 7196805 & 827 & 4,21 & 2 & 10,19 & 2 & 10,19 & 0 & 0 & & 0 & 0 \\
\hline
\end{tabular}

a borda da malha de amostragem, o mesmo é considerado na contagem dos lineamentos, ocasionando, conseqüentemente, desvios na análise. Segundo Mauldon et al. (2000) e Rohrbaugh et al. (2002), para se obter a densidade real, deve-se medir o número de nós e dividir este valor pela área do círculo. Os nós, neste caso, são os pontos médios de cada segmento. Aqueles que caírem dentro da mesma área, serão utilizados no cálculo, desde que o segmento esteja, no mínimo, $50 \%$ incluso na malha. Nesta situação, o comprimento de cada lineamento tem influência direta no cálculo de densidade. Aqueles traços que apenas tocam as bordas ou estão parcialmente inseridos na região serão ignorados. Uma forma de testar o efeito do raio na sobrestimação ou subestimação é comparar a densidade real com a densidade aparente, conforme mostrado na figura 9.

$\mathrm{Na}$ figura 9, de acordo com os cálculos realizados para a mesma região (exemplo teórico), utilizandose três diferentes raios para a amostragem circular, é possível verificar qual é o raio de amostragem onde há a melhor aproximação dos valores de densidade real e densidade aparente. No exemplo apresentado, a densidade real calculada para as três áreas de amostragem é sempre a mesma, confirmando o conceito empregado. Quanto à densidade aparente, o círculo médio está onde os valores de $\mathrm{D}_{\mathrm{r}}$ e $\mathrm{D}_{\mathrm{ap}}$ mais se aproximam. Na presente análise, foram feitos testes com diferentes raios de amostragem, buscando identificar o tamanho mais adequado para interpolar a densidade aparente das fraturas.

Com base na relação de densidade real e densidade aparente, verificou-se que, na área considerada no Complexo Atuba, o raio de amostragem mais apropriado para gerar o mapa de densidade de fraturas é aquele de valor igual a $4000 \mathrm{~m}$, conforme pode ser observado no detalhe da figura 10 (A) e na tabela 2 . O resultado da interpolação é mostrado na figura 10 (B).

Apesar de terem sido interpolados mapas de densidade aparente de fraturas, constatou-se baixa cor- 


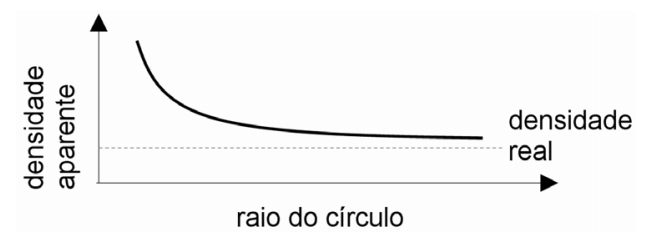

Figura 7 - Relação que mostra a dependência entre o raio e a densidade real e aparente (mod.de Rohrbaugh et al,. 2002).
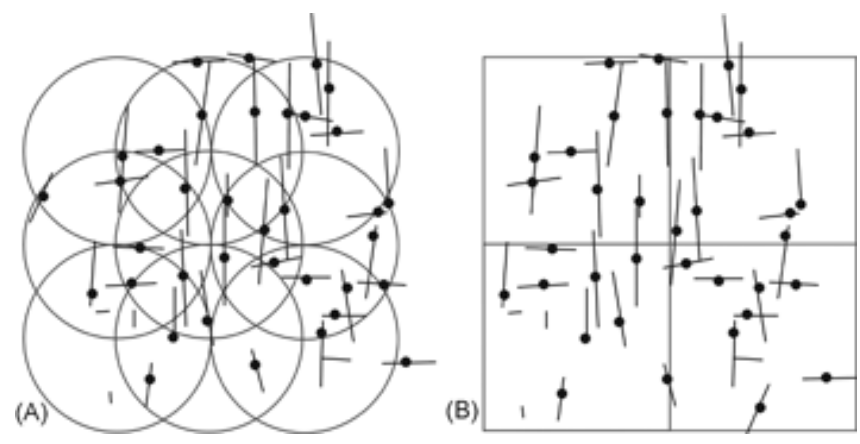

Figura 8 - Exemplos de dois tipos de amostragens de lineamentos. (a) Malha circular; (b) Malha retangular.

\begin{tabular}{|c|c|}
\hline $\begin{array}{l}\text { Densidade real: } \\
\mathrm{D}_{r}: \mathrm{n}^{\circ} \text { nós/área }\left(\pi \cdot \text { raio }^{2}\right)\end{array}$ & $\begin{array}{l}\text { Círculo grande }(\mathrm{r} 75 \mathrm{~m}) \\
\text { Densidade real } \\
\mathrm{D}_{\mathrm{r}}=36 / 17662,5=0,00203 \text { por } \mathrm{m}^{2} \\
\text { Densidade aparente } \\
\mathrm{D}_{\mathrm{ap}}=41 / 17662,5=0,00232 \text { por } \mathrm{m}^{2}\end{array}$ \\
\hline 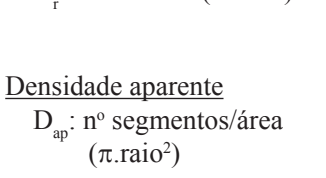 & $\begin{array}{l}\text { Círculo médio }(\mathrm{r} 25 \mathrm{~m}) \\
\text { Densidade real } \\
\mathrm{D}_{\mathrm{r}}=18 / 17662,5=0,00203 \text { por } \mathrm{m}^{2} \\
\text { Densidade aparente } \\
\mathrm{D}_{\mathrm{ap}}=17 / 17662,5=0,00216 \text { por } \mathrm{m}^{2}\end{array}$ \\
\hline & $\begin{array}{l}\text { Cículo menor }(25 \mathrm{~m}) \\
\text { Densidade real } \\
\mathrm{D}_{\mathrm{r}}=4 / 17662,5=0,00203 \text { por } \mathrm{m}^{2} \\
\text { Densidade aparente } \\
\mathrm{D}_{\text {ap }}=6 / 17662,5=0,00305 \text { por } \mathrm{m}^{2}\end{array}$ \\
\hline
\end{tabular}

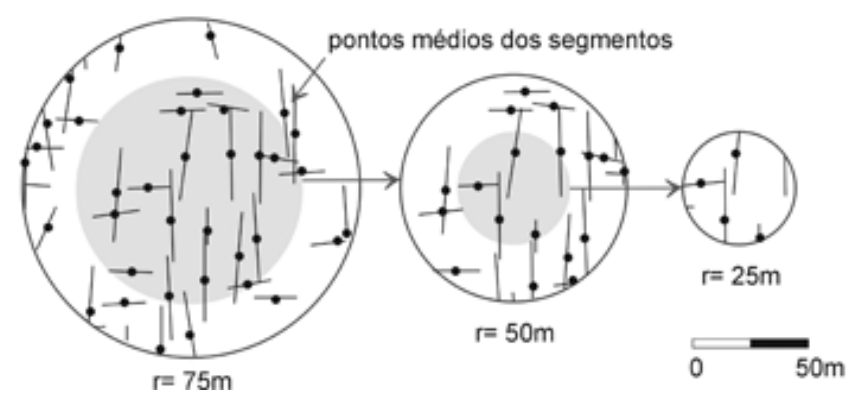

Figura 9 - Esquema que mostra o cálculo da densidade real e aparente (mod. de Rohrbaugh et al., 2002).

relação dos mesmos com os valores reais de vazão e capacidade específica dos poços tubulares no município, demonstrando que o parâmetro densidade não deve ser considerado de forma isolada para avaliar a favorabilida- de hidrogeológica da área de estudo. Na literatura vários autores criticam o uso apenas deste parâmetro como forma de avaliação de circulação de água subterrânea, pois, com freqüência, o que se observa é que redes densas de fraturas não estão necessariamente hidraulicamente conectadas. Por esta razão, é vital a compreensão da tectônica rúptil, sendo a intersecção dos planos nas famílias de fraturas conjugadas, por exemplo aquelas relacionadas ao campo de tensão mais recente, o fator de maior importância (Berkowitz 2002, Odling et al. 1999). Para os autores, a conectividade em um sistema de fraturas depende da orientação dos planos (segundo o campo de tensão atual) e da distribuição do tamanho dos mesmos (Balberg \& Binenbaum 1983). Portanto, a inclusão das falhas de grande porte é fundamental na análise.

RESULTADOS Em termos de favorabilidade para água subterrânea, o parâmetro intersecção das fraturas, calculado por meio da extensão Lineament Analysis, é o que melhor apresentou correlação com as variáveis hidrogeológicas. Após terem sido realizados testes com diferentes raios de busca e diferentes famílias de fraturas, o cálculo do parâmetro de intersecção com um raio de $250 \mathrm{~m}$, ou até $500 \mathrm{~m}$, onde são considerados somente os planos conjugados e as falhas mestras, apresenta boa coincidência com os valores reais de vazão e capacidade específica medidas nos poços tubulares profundos. Ao contrário do parâmetro da densidade de fraturas, ao escolher o raio de busca para os planos de intersecção, quanto menor o círculo, maior é a representatividade da malha. Para representar este parâmetro, os valores obtidos com o cálculo realizado pela extensão de análises de lineamentos foram interpolados utilizando-se a krigagem pelo programa SURFER, resultando em diferentes mapas de contornos reamostrados no programa ARCGIS. Para testar a variabilidade e anisotropia dos dados, foram elaborados variogramas com os resultados do parâmetro da intersecção. A primeira imagem (Fig. 11) mostra as estruturas principais da área sobrepostas ao mapa de contornos, representando a intersecção de fraturas no intervalo entre N45W a N45E por meio de uma escala de cores (vermelho: valores altos de conectividade; cinza: valores baixos de conectividade). Na figura 12 (A) pode ser visto apenas o resultado do cálculo do parâmetro de intersecção. Nesta imagem, na parte central da cidade, onde há o maior número de informações, foi traçado um polígono que delimita uma área menor para ser apresentada posteriormente na figura 14 (A e B).

Também foram realizados testes com todos os lineamentos mapeados ou com os planos no intervalo entre N65W a N65E (Fig. 12 B). O padrão encontrado em ambas as situações foi bem diverso daquele observado só com as fraturas conjugadas, não tendo havido boa correspondência com os valores reais de vazão ou com a capacidade específica. Com a inclusão de todos os lineamentos da área ou mesmo daqueles no intervalo de N65W a N65E há uma grande sobrestimação do parâmetro de intersecção na porção norte do município de Curitiba.

Nos variogramas confeccionados para ambos os intervalos de fraturas (Fig. 13 A e B), a direção de 

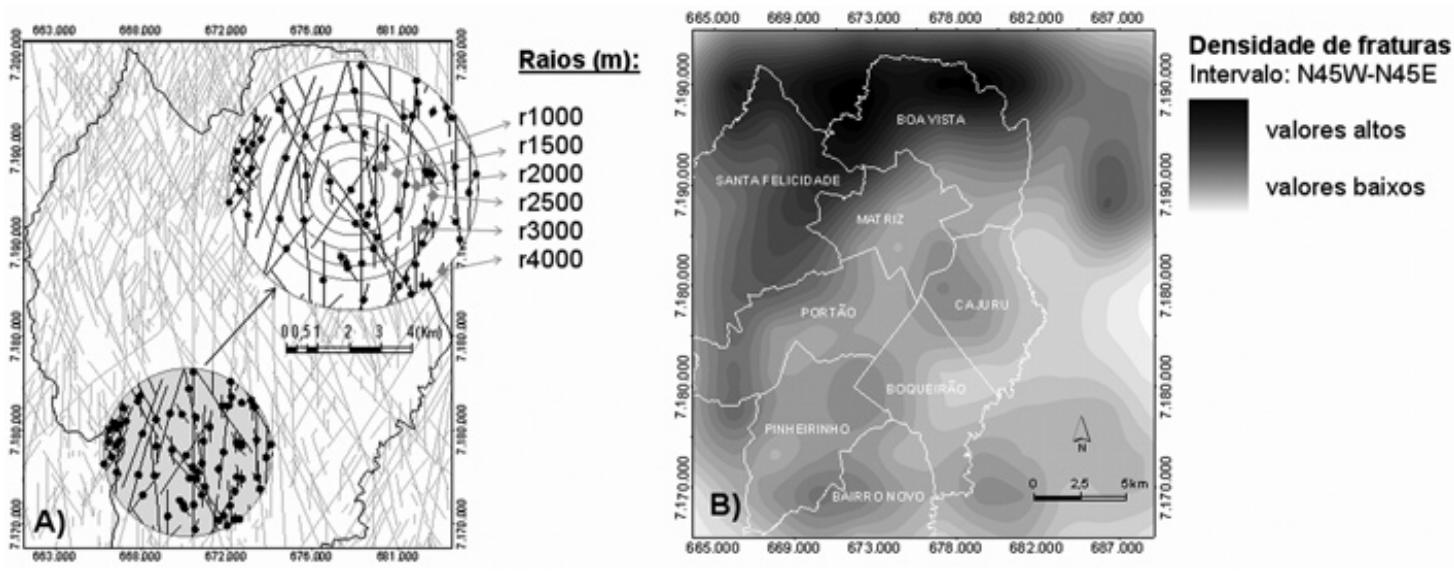

Figura 10 - Testes com diferentes raios de amostragem, buscando identificar o tamanho mais adequado para interpolar a densidade aparente das fraturas, na região de Curitiba. (A) Detalhe mostrando os diferentes raios testados para realizar o cálculo de densidade de fraturas; $(B)$ Mapa de contornos que mostra os valores obtidos para o parâmetro de densidade de fraturas utilizando o intervalo dos planos entre $N 45 W$ a N45E.

Tabela 2 - Valores calculados para a densidade real e aparente nas áreas de amostragem do detalhe da figura 10.

\begin{tabular}{c|c|c|c|c|c}
\hline Círculo (raio) & Área $\left(\mathrm{m}^{2}\right)$ & $\mathrm{n}^{0}$ segmentos & Pontos médios & Densidade Real & Densidade Aparente \\
\hline circulo r1000 (m) & 3140000 & 9 & 5 & 0,000002 & 0,000003 \\
\hline circulo r1500 (m) & 7065000 & 15 & 8 & 0,000001 & 0,000002 \\
\hline circulo r2000 (m) & 12560000 & 26 & 16 & 0,000001 & 0,000002 \\
\hline circulo r2500 (m) & 19625000 & 39 & 25 & 0,000001 & 0,000002 \\
\hline circulo r3000 (m) & 28260000 & 49 & 35 & 0,000001 & 0,000002 \\
\hline circulo r4000 (m) & 38465000 & 90 & 68 & 0,000002 & 0,000002 \\
\hline
\end{tabular}

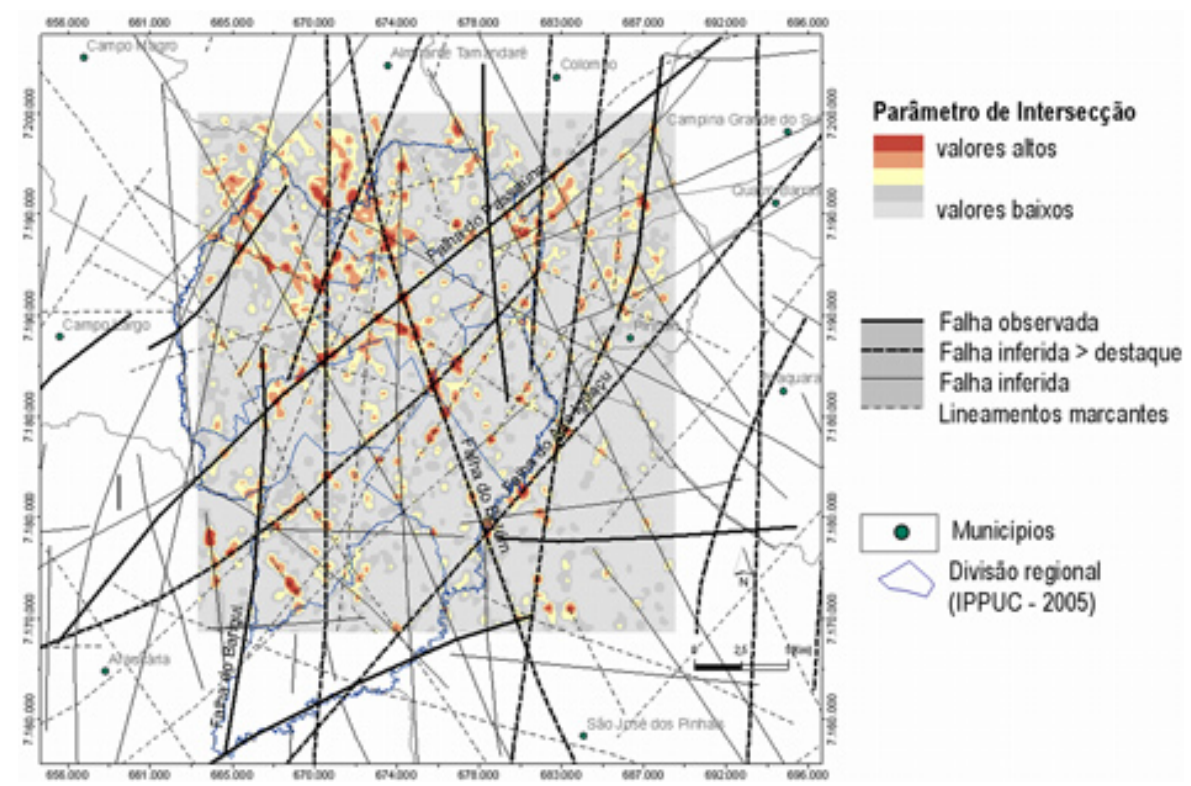

Figura 11 - Planos tectônicos de maior destaque na escala regional, sobrepostos ao mapa de contornos mostrando os valores obtidos para o parâmetro de intersecção de fraturas no intervalo N40W a N40E.

maior continuidade e menor variância dos dados foi a N-S $\left(90^{\circ}\right)$. O gráfico onde o ajuste empregando o mode- 

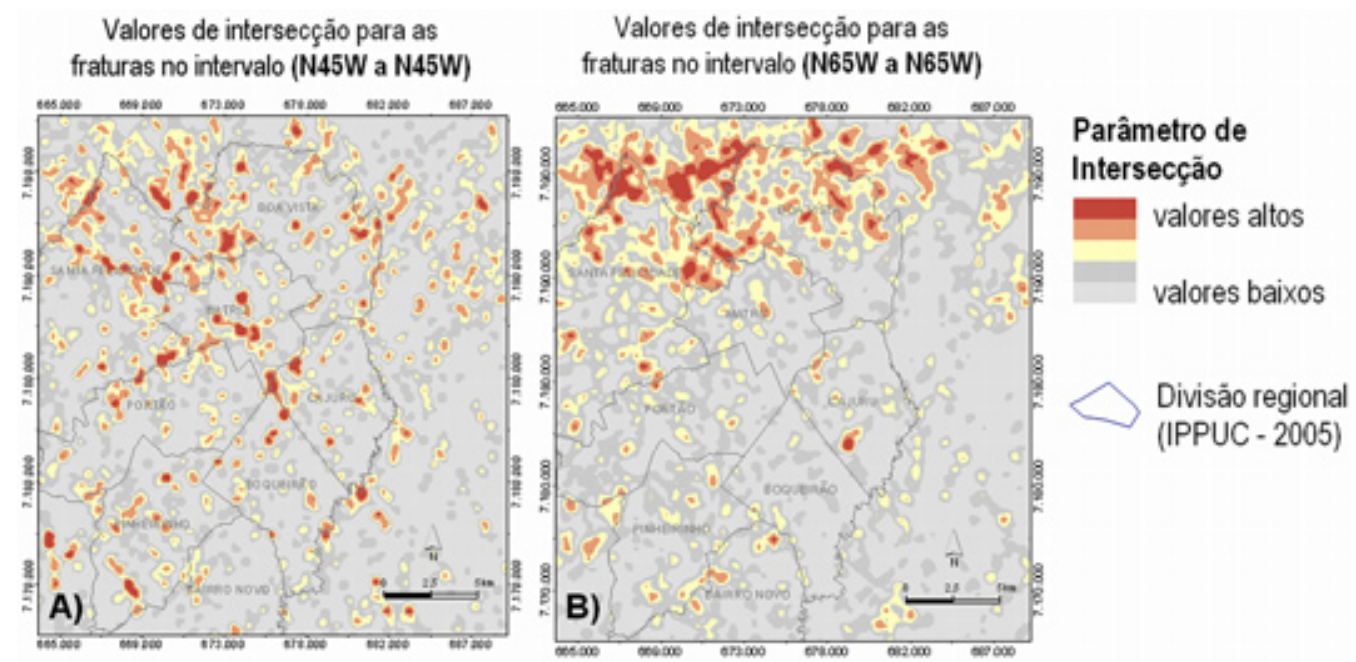

Figura 12 - Dois diferentes resultados do parâmetro de intersecção das fraturas, calculados por meio da extensão Lineament Analysi. (A) e (B) Comparação entre os mapas com os valores obtidos para o cálculo da intersecção para as fraturas nos intervalos $N 40 \mathrm{~W}$ a N40E e N65W a N65E.
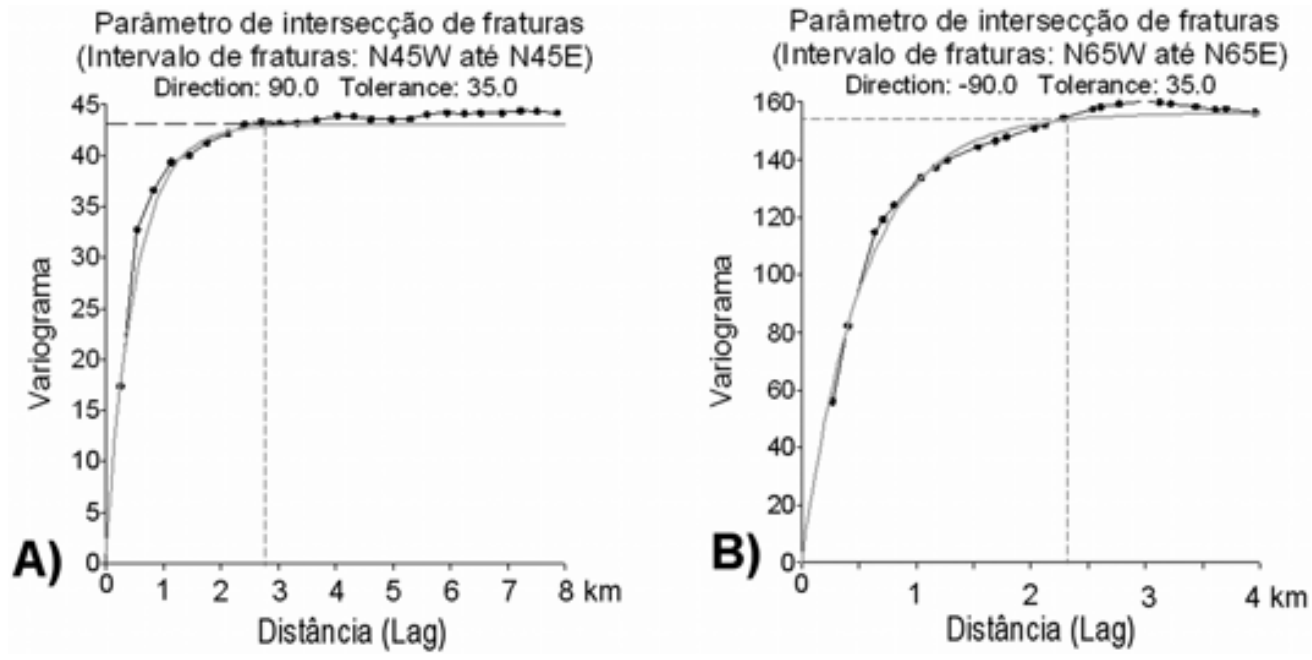

Figura 13 - Variogramas confeccionado para as fraturas nos intervalos (A) N45W a N45E e (B) N65W a N65E.

lo esférico mostrou os menores erros e maior continuidade das variáveis, foi o confeccionado com os valores de intersecção das fraturas somente no intervalo N45W a N45E (com o tensor $\sigma_{1}$ na direção N-S, o que corresponde a fase $\mathrm{D}_{2}$ de Salamuni 1998). Isso é mais um indicativo de que, embora a região apresente fraturas em quase todas as direções, em termos hidrogeológicos destacam-se os planos conjugados e as falhas mestras associadas ao campo de tensão mais recente ou pré-atual. Ao serem comparadas as estruturas com o resultado obtido, verifica-se que os grandes planos tectônicos estão posicionados, na maioria, sobre valores altos do parâmetro de intersecção. Dentre todas as descontinuidades, destaca-se a falha inferida sobre o alinhamento de relevo onde estão encaixados o rio Belém, a falha do Passaúna e os planos N-S (ver Fig. 11). Segundo
Odling et al. (1999), a maior conectividade de fraturas pode ser definida quantitativamente como proporcional ao comprimento total do traço que pertence ao agrupamento (cluster) mais largo e, como se observa na área em análise, as falhas mestras, assim como os planos conjugados, têm grande influência sobre a circulação da água subterrânea no aqüífero fraturado. Os planos conjugados são responsáveis pela conexão da rede, o que justifica a utilização das fraturas no modelo estrutural proposto por Chavez-Kus (2008).

Quanto à densidade de fraturas, embora tenham sido feitos testes buscando o raio apropriado para a representação deste parâmetro, observando a figura 12 (B), torna-se claro que a variável serve apenas como referencial das áreas de maior densidade de lineamentos e, como esperado, o mesmo ocorre na porção noroeste 
de Curitiba, nas áreas aflorantes das rochas do Complexo Atuba. No entanto, em termos hidrogeológicos, a variável não apresenta resultados decisivos, ao contrário do parâmetro de intersecção das fraturas (Fig. 11), cujas concentrações coincidem na maior parte com os valores altos de vazão e capacidade específica.

Para mostrar esta relação no item seguinte, os valores de capacidade específica e vazão dos poços tubulares profundos foram inseridos no mapa de contornos com a variável intersecção de fraturas no intervalo entre $\mathrm{N} 45 \mathrm{~W}$ a N45E.

$\mathrm{Na}$ figura 14 (A) foi escolhido um detalhe mais aproximado na porção central do município que mostra, em segundo plano, os limites dos bairros e as falhas mestras. Neste detalhe, sobreposto ao mapa de intersecção, comparou-se os valores baixos (triângulos pretos) e os mais elevados de vazão (círculos em tons de azul). Ainda que alguns poços mais favoráveis sejam observados sobre porções com valores baixos de intersecção (manchas cinzas) e vice-versa (manchas avermelhadas), a correlação entre as variáveis é grande. Ver a localização do poço mais produtivo no município nos cruzamentos de dois grandes planos de falhas e outro agrupamento de poços produtivos delimitados com um círculo em vermelho também em uma área com grande número de intersecção de fraturas. Na figura 14 (B) foram plotadas as sondagens com vazões baixas a médias e os valores improdutivos. Os desvios são maiores,

(A)

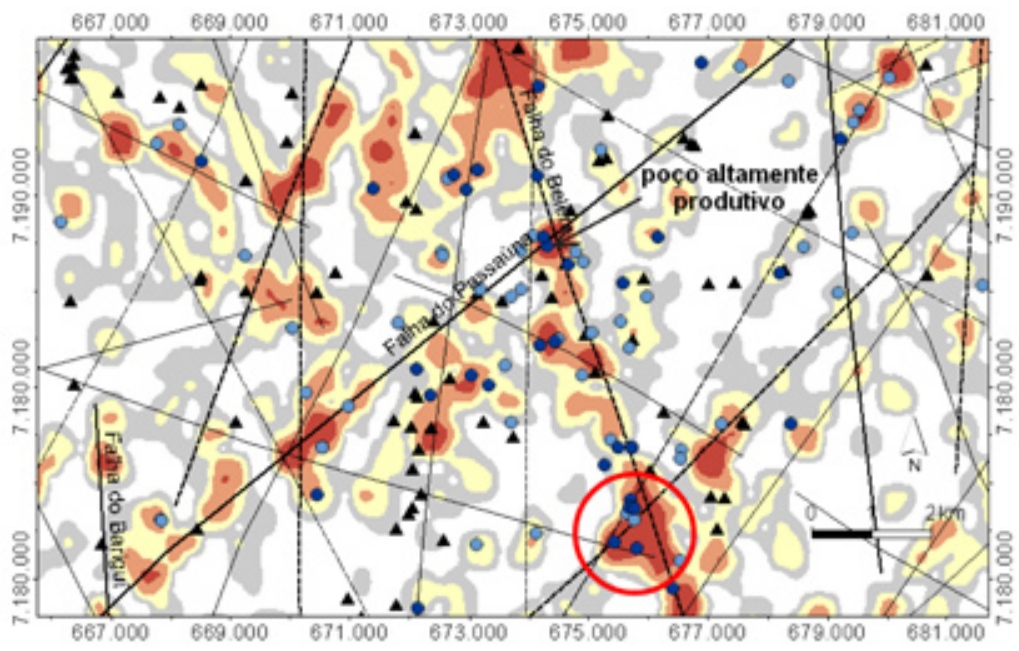

(B)
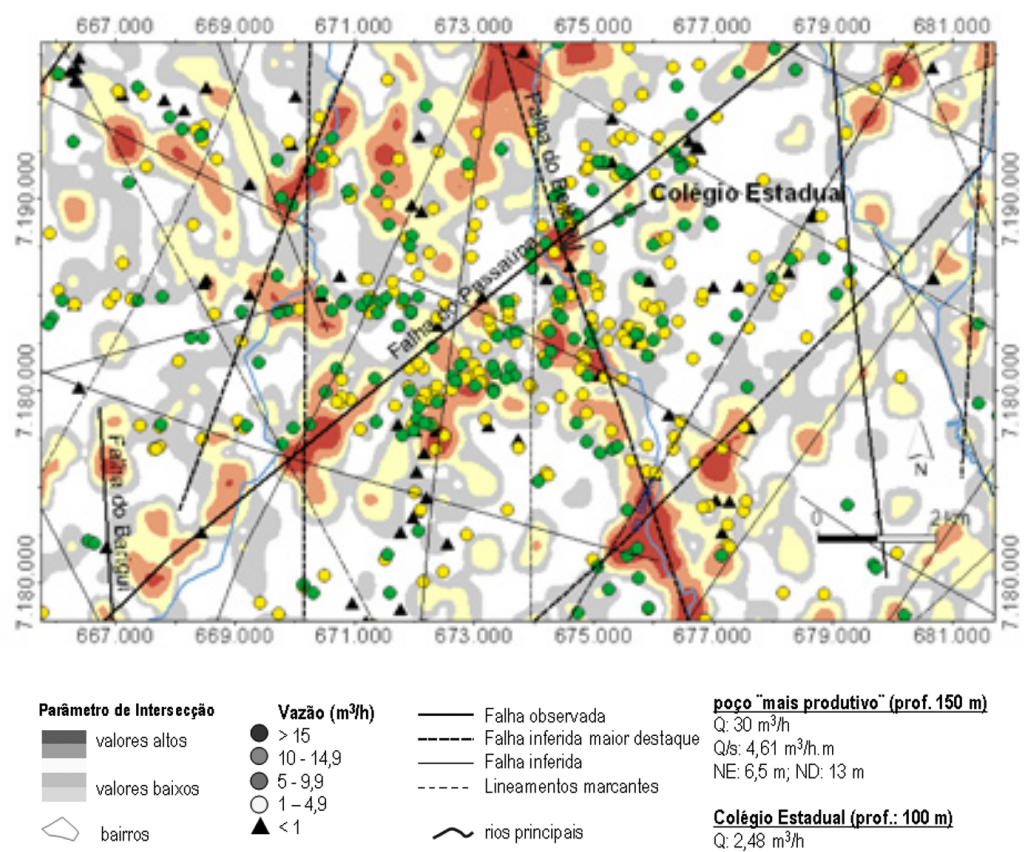

Figura 14 - Detalhe que mostra, com maior aproximação, a variável vazão (Q) e as estruturas principais sobrepostas ao mapa de contornos com os valores de intersecção de fraturas. (A) Valores baixos (triângulos) e os mais elevados de vazão (círculos em tons de azul). Em (B) foram plotadas as sondagens com vazões baixas a médias e os valores improdutivos. 


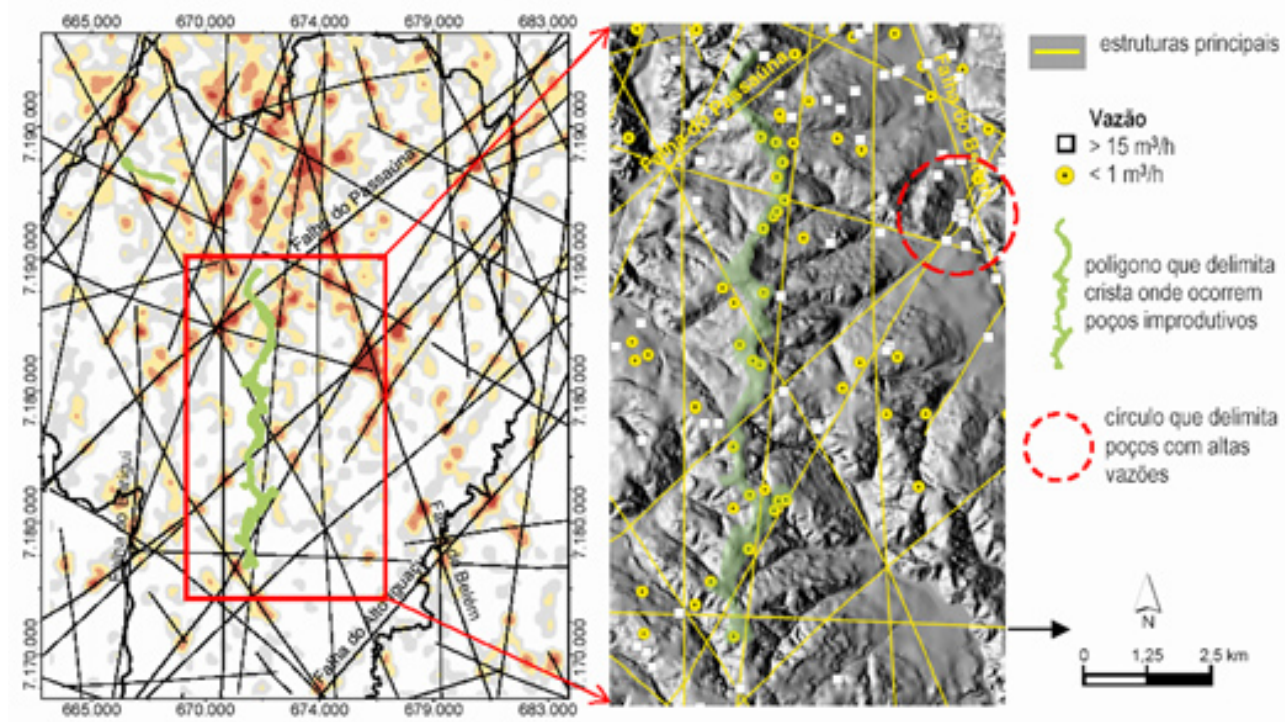

Figura 15 - Visão integrada com o resultado obtido no cálculo do parâmetro de intersecção versus os planos estruturais de grande porte (escala regional) na região de Curitiba. (a) Estruturas principais sobrepostas ao mapa de contornos com os valores de intersecção para as fraturas no intervalo $N 45 \mathrm{~W}$ a N45E. O polígono verde delimita uma área onde constatou-se grande número de poços improdutivos; (b) Detalhe da crista que mostra variável vazão (círculos e quadrados) e estruturas principais sobrepostas ao MDR. O circulo em vermelho demarca agrupamento de poços com altas vazões.

no entanto, é indiscutível que a maior favorabilidade corresponde aos cruzamentos das falhas mestras é indiscutível a maior favorabilidade. Nestes locais, há ausência de poços improdutivos e predominam os círculos verdes (vazões médias) em relação aos círculos amarelos (vazões mais baixas).

Situação contrária às áreas favoráveis foi constatada ao longo de uma crista na porção central da cidade de Curitiba (Fig. 15 A). Os poços perfurados sobre esta feição geomorfológica positiva (demarcada com um polígono em verde) possuem vazão inferior a $1 \mathrm{~m}^{3} / \mathrm{h}$. A morfologia superior controlada pelas cristas é, portanto, de menor interesse hidrogeológico. Já as sondagens realizadas junto às estruturas tectônicas que seccionam este alto topográfico demarcado na figura 15 (B), principalmente no cruzamento dos planos maiores de fraturamento, são produtivas.

CONCLUSÃO Com base no modelo estrutural proposto por Chavez-Kus (2003) e Chavez-Kus \& Salamuni (2008), $\sigma_{1}$ está ou esteve orientado na direção N-S. Neste contexto, foram realizados os cálculos de intersecção de fraturas somente com os planos considerados mais favoráveis para explotação de água subterrânea (Fig. 4). O resultado obtido mostra que o parâmetro de intersecção nos cruzamentos dos planos conjugados e fraturas híbridas coincidem com valores altos de capacidade específica e vazão dos poços tubulares profundos. As falhas de grande porte que controlam os principais limites entre os blocos estruturais do Complexo Atuba, no embasamento da Bacia de Curitiba, por exemplo, estão sempre presentes onde ocorrem valores de intersecção também altos (Fig. 11 e 14). A coincidência maior pode ser vista no cruzamento da falha do Belém com as demais estruturas.

O poço apontado na figura 14 (A), com $150 \mathrm{~m}$ de profundidade é o melhor exemplo em Curitiba de produtividade excepcional com uma vazão de $30 \mathrm{~m} / \mathrm{h}$, capacidade específica $4,61 \mathrm{~m}^{3} / \mathrm{h} . \mathrm{m}$ e rebaixamento menor que $1 \mathrm{~m}$, utilizando-se uma bomba de 8 polegadas. A sondagem (orientada e acompanhada por Eduardo Salamuni) foi locada exatamente no ponto de intersecção entre as falhas do Passaúna e a falha do Belém, região considerada como altamente favorável segundo o resultado do cálculo do parâmetro de intersecção. Pela observação de E. Salamuni a perfuração interceptou uma grande área fraturada (falha empinada) onde foram, inclusive, identificadas estrias de atrito na rocha amostrada. Por outro lado, no Colégio Estadual, vizinho ao local acima citado, no poço tubular com $100 \mathrm{~m}$ de profundidade (Fig. 14, B) a vazão encontrada foi de apenas $2,5 \mathrm{~m}^{3} / \mathrm{h}$. Isso ilustra a grande heterogeneidade e anisotropia do Aqüífero Atuba, materializada pelas variações de produtividade dos poços tubulares profundos, com vazões e capacidades específicas variando lado a lado de improdutivos até os valores máximos de $44 \mathrm{~m}^{3} / \mathrm{h}(\mathrm{Q})$ e $19 \mathrm{~m}^{3} / \mathrm{h} \cdot \mathrm{m}(\mathrm{Q} / \mathrm{s})$. Verifica-se também aqui que os poços locados em região com baixa intersecção de fraturas apresentam produtividade baixa ou nula em comparação a poços produtivos locados onde há maior quantidade de intersecção de planos tectônicos. Outro exemplo notável de poço com alta vazão que ocorre em intersecção de grandes estruturas como a já mencionada falha do Belém foi delimitado com círculo vermelho na figura 14 (A). Situação oposta 
é constatada em áreas topograficamente mais elevadas, como em uma crista alongada no centro da cidade, na qual a favorabilidade hidrogeológica é baixa (ver Fig. 15 A), exceto junto ou nos cruzamentos das estruturas transcorrentes que cortam esta feição geomorfológica, onde há poços produtivos (Fig. $15 \mathrm{~B}$ ).

As relações anteriores demonstram que as propriedades hidráulicas do meio geológico e a produtividade em termos hidrogeológicos de uma região não devem ser diretamente inferidas usando como critério somente as áreas próximas ou ao redor dos lineamentos. Na região, os testes realizados para gerar mapas de densidade de fraturas mostram que as variáveisl Q $\mathrm{e} \mathrm{Q} / \mathrm{s}$ não apresenta boa correspondência com a produtividade dos poços. Em termos de favorabilidade para água subterrânea, o parâmetro de intersecção das fraturas, calculado por meio da extensão Lineament analysis for geology and groundwater field, é o que melhor apresenta correlação com as variáveis hidrogeológicas, desde que a escolha das feições lineares para o cálculo do parâmetro de intersecção seja feita com base nas investigações estruturais de campo e análises morfotectônicas. Com a inclusão, por exemplo, de todos os lineamentos traçados com auxílio de fotointerpretação ou do MDR, o mapa com a variável do parâmetro de intersecção mostra-se pouco correlacionável com os valores reais de vazão e/ou capacidade específica dos poços tubulares profundos. Esse teste confirma, portanto, a importância de se efetuar a seleção dos lineamentos de acordo com a trama estru- tural mais recente, já que planos não reativados tendem a ser mais fechados.

Para o aqüífero em questão a maior favorabilidade hidrogeológica é fortemente condicionada pelo parâmetro de intersecção, com peso ainda maior nos cruzamentos das estruturas de grande porte. O cálculo do parâmetro de intersecção mostrou-se válido quando aliado à seleção criteriosa dos planos de fraturas com base no modelo estrutural apresentado por Chavez-Kus (2003) e Chavez-Kus et al. (2008). Neste modelo, que teve como referência os planos de Riedel como sugerido por Kim (2004), considera-se como os planos mais favoráveis para explotação de água subterrânea os que fazem parte do sistema transcorrente N-S (onde o $\boldsymbol{\sigma} 1$ está ou esteve orientado na direção N-S), ou seja, os planos associados e conjugados no intervalo $\mathrm{N} 45 \mathrm{~W}$ a $\mathrm{N} 45 \mathrm{E}$, especialmente os de grande magnitude.

Em vista do exposto, demonstra-se que o uso das ferramentas automáticas de sistema de informação, com base apenas em fraturas abertas associadas à tensão atual ou pré-atual ajustadas ao modelo de Riedel, é efetivo no apontamento de áreas favoráveis à circulação de água subterrânea na região.

Agradecimentos Este trabalho recebeu o apoio financeiro da Fundação Coordenação de Aperfeiçoamento de Pessoal de Nível Superior - CAPES (bolsa de doutorado no Brasil e Bolsa de Estágio de Doutorando no Exterior / Processo 1897047, primeiro autor). Aos revisores da RBG pelas sugestões ao manuscrito.

\section{Referências}

Allen C.R. 1975. Geological criteria for evaluating seismicity, Geol. Soc. Am. Bull., 86:1041-1056.

Balberg I. \& Binenbaum N. 1983. Computer study of the percolation threshold in a two-dimensional anisotropic system of conducting sticks. Phys. Rev., B28:3799-3812.

Cartwright J.A., Mansfield C.S., Trudgill B.D. 1996. The growth of normal faults by segment linkage. In: Buchanan P.G., Nieuwland D.A. (eds.) Modern Developments in Structural Interpretation, Validation and Modelling. Geol. Soc. of London Special Publication, 99:163-177.

Chavez-Kus L. 2003. Análise da tectônica rúptil em rochas do embasamento da Bacia de Curitiba com vistas à determinação de áreas favoráveis à exploração de água subterrânea. Dissertação de Mestrado, Departamento de Geologia, UFPR, 216p.

Chavez-Kus L. 2008. Modelo de funcionamento do Aqüifero Atuba com base em parâmetros estruturais e hidrogeológicos, município de Curitiba. Tese de Doutoramento, Departamento de Geologia, UFPR, 239p.

Chavez-Kus L. \& Salamuni E. 2008. Evidência de tensão N-S intraplaca no Neógeno, Complexo Atuba - região de Curitiba. Rev. Bras. Geoc., 38(3):439-454.

Connolly P. \& Cosgrove J. 1999. Prediction of static and dynamic fluid pathways within and around dilational jogs. In: McCaffrey K., Lonergan L., Wilkinson J. (eds.) Fractures, Fluid Flow and Mineralisation. Geol. Soc. of Lon- don, Special Publications, 155:105-121.

Cristofoletti A. 1980. Geomorfologia. 2a ed. São Paulo, Edgard Blucher, 188p.

Hardcastle K.C. 1995. Photolineament factor: A new computer-aided method for remotelys fractured. Photogrammetric. Engineering and Remote Sensing, 61(6):739747.

Hobbs W.H. 1912. Earth features and their meaning. New York Macmillan Co., 506p.

IPPUC. 2005. Mapa de Arruamentos de Curitiba. Mapa e Lei de Zoneamento. Curitiba, IPPUC, CD-Rom.

Khang N.D., Watanabea K., Saegusab H. 2004. Fracture step structure: geometrical characterization and effects on fluid flow and breakthrough curve. Engineering Geology, 75(1):107-127.

Kim G-B., Lee J-Y., Lee K-K. 2004. Construction of lineament maps related to groundwater occurrence with Arcview and Avenue scripts. Computers and Geosciences, 30(9/10):1117-1126.

Kim G. 2004. Lineament analysis for geology and groundwater field. Disponível em: http://arcscripts.esri.com/, Acessado em 01/112004. (Lineament-analysis-english20040623.zip) pode ser obtida gratuitamente a partir da página da WEB da ESRI (Support Center, Last modified 4 July 2004).

Martel S.J. \& Pollard D.D. 1989. Mechanics of slip and frac- 
ture along small faults and simple strike-slip fault zones in granitic rock. J. Geophys. Res., 94:9417-9428.

Mauldon M., Dunne W.M., Rohrbaugh M.B.Jr. 2001. Circular scanlines and circular windows: new tools for characterizing the geometry of fracture traces. J. Struct. Geol., 23:247-258.

Mccaig A.M. 1989. Fluid flow through fault zones. Nature, v. 340 , Issue $6235,600 \mathrm{p}$.

Odling N.E., Gillespie P.A., Bourgine B., Castaing C, Chiles J.P., Christiansen N.P., Eeles M., Fillion E., Genter A., Madsen L., Olsen C., Trice R., Walsh J.J., Watterson J. 1999. Variations in fracture system geometry and their implications for fluid flow in fractured hydrocarbon reservoirs. Petroleum Geoscience, 5:373-384.

O’leary D.W., Friedman J.D., Pohn H.A. 1976. Lineament, linear lineation some proposed new standards for old terms. Geological Society America Bulletin, 87:14631469.

Riedel W. 1929. Zur mechanik geologischer brucherscheinungen. Ein beitrag zum problem der fiederspalten. Zentralblat fur Mineralogie. Verlagsbuchhandlung, 1919b:354-368.

Rohrbaugh M.B., Dunne Jr. W.M., Mauldon M. 2002. Estimating fracture trace intensity, density, and mean length using circular scan lines and windows. American Association of Petroleum Geologists (AAPG) Bulletin, 86(12):2089-2104.

Salamuni E. 1998. Tectônica da Bacia Sedimentar de Curitiba (PR). Tese de Doutoramento, Inst. Geoc. e Ciências
Exatas, UNESP, Rio Claro (SP), 214p.

Sibson R.H. 1987. Earthquake rupturing as a mineralizing agent in hydrothermal systems. Geology, 15:701-704.

Siga Jr O., Basei M. A.S., Reis Neto J.M., Machiavelli A., Harara O.M. 1995. O Complexo Atuba: um cinturão Paleoproterozóico intensamente retrabalhado no Neoproterozóico. Boletim IG-USP Série Científica, 26:69-98.

Smellie J.A.T., Laaksoharju M., Wikberg P. 1995. Aspo, SE Sweden: a natural groundwater flow model derived from hydrogeochemical observations. J. Hydrol., 172:145169.

Tripp G.I. \& Vearn J.R. 2004. Fault/fracture density and mineralization: a contouring method for targeting in gold exploration. J. Struct. Geol., 26:1087-1108.

Watanabe K., Sugimura Y., Morita Y., Tanaka T. 1997. Channel network modeling of the fractured granite in the Himachi area, Japan. In: Kanaori Y. (ed.) Earthquake proof design and active faults. Elsevier Sci., p.247-262.

Yoshida H., Aoki K., Semba T., Ota K., Aman O.K., Hama K., Kawamura M., Tsubota K. 2000. Overview of the stability and barrier functions of the granitic geosphere at the Kamaishi Mine: relevance to radioactive waste disposal in Japan. Engineering Geology, 56:151-162.

Manuscrito ID 11106

Submetido em 14 de abril de 2008

Aceito em 20 de setembro de 2008

Sistema eletrônico de submissão 